\title{
Removal of Pharmaceuticals from Water: Conventional and Alternative Treatments
}

\author{
Ricardo N. Coimbra ${ }^{1}\left(\mathbb{D}\right.$, Carla Escapa ${ }^{2}(\mathbb{D})$ and Marta Otero ${ }^{1,3, *(\mathbb{D})}$ \\ 1 Department of Environment and Planning, University of Aveiro, 3810-193 Aveiro, Portugal; \\ ricardo.coimbra@ua.pt \\ 2 Department of Applied Chemistry and Physics, Institute of Environment, \\ Natural Resources and Biodiversity (IMARENABIO), Universidad de León, 24071 León, Spain; \\ carla.escapa@unileon.es \\ 3 Centre for Environmental and Marine Studies (CESAM), University of Aveiro, 3810-193 Aveiro, Portugal \\ * Correspondence: marta.otero@ua.pt
}

check for updates

Citation: Coimbra, R.N.; Escapa, C.; Otero, M. Removal of

Pharmaceuticals from Water:

Conventional and Alternative

Treatments. Water 2021, 13, 487.

https://doi.org/10.3390/w13040487

Received: 30 January 2021

Accepted: 9 February 2021

Published: 13 February 2021

Publisher's Note: MDPI stays neutral with regard to jurisdictional claims in published maps and institutional affiliations.

Copyright: (c) 2021 by the authors. Licensee MDPI, Basel, Switzerland. This article is an open access article distributed under the terms and conditions of the Creative Commons Attribution (CC BY) license (https:/ / creativecommons.org/licenses/by/ $4.0 /)$.

\section{Introduction}

Freshwater represents around $2.5 \%$ of all water on Earth, with less than $1 \%$ being accessible. Furthermore, climate change and direct human impacts are dramatically reducing freshwater availability worldwide [1]. Conversely, due to demographic growth, industry development, and the improvement in living conditions, freshwater demand has been continuously increasing. Apart from quantity, water quality is also essential. Indeed, "clean water and sanitation" makes part of the seventeen Sustainable Development Goals by the United Nations. Among the threats to water quality is the occurrence of micropollutants, which include agrochemicals, steroid hormones, personal care products, and pharmaceuticals, which are present at trace levels in the aquatic environment, where they are released by different routes through human activity [2].

In natural waters, pharmaceuticals are micropollutants that mainly come from the after consumption excretion of a non-metabolized fraction and/or metabolites from the original drug. These substances, together with pharmaceuticals wrongly disposed of through the toilet, end up in the municipal wastewater treatment plants (WWTP), which were not designed to remove these sorts of pollutants, but only regulated parameters $[3,4]$.

The nonexistence of discharge limits for pharmaceuticals, which were not traditionally viewed as pollutants, is the main reason for the widespread of these substances. However, their detection in the aquatic environment [2], together with their potential to cause physiological responses in non-target individuals [4,5], raised alarms at the end of the 1990s. Then, pharmaceuticals' detection in drinking water sources made it evident that the effects on human health were not irrelevant $[4,6,7]$.

Concern about the negative effects of pharmaceuticals' presence in the environment has lately led to decisions at a legislative level to determine associated risks. Within the European Union (EU), Directive 2000/60/EC (Water Framework Directive (WFD)) has been the most comprehensive initiative regarding water protection. WFD launched a strategy to define high-risk substances to be prioritized, with 33 priority substances and their corresponding environmental quality standards being ratified by Directive 2008/105/EC. This Directive also set up the establishment of a watch list of 10 substances, in the first instance, which should be monitored across the EU to gather support information for future prioritization exercises. The list was planned to be dynamic and updated every two years so to respond to new information on the potential risks. Then, Directive 2013/39/EU established that the non-steroid anti-inflammatory diclofenac, the synthetic hormone 17alpha-ethinylestradiol (EE2), and the natural estrogen 17-beta-estradiol (E2) should be included in the first watch list. Accordingly, Decision 2015/495/EU set the definite first watch list, which, besides the referred substances, also contained three macrolide antibiotics, namely azithromycin, clarithromycin, erythromycin, and another natural estrogen, viz. 
estrone (E1). Decision 2018/840/EU indicated that sufficient high-quality monitoring data were only available on diclofenac, which was removed from the list; the rest of the pharmaceuticals remained on the second list, which also added the antibiotics amoxicillin and ciprofloxacin. Recently, Decision 2020/1161/EU established that, since four years is the maximum that any substance may be on the watch list, EE2, E2, E1, and macrolide antibiotics should be removed while amoxicillin and ciprofloxacin should be maintained in the third watch list. This Decision, in agreement with the EU Strategic Approach to Pharmaceuticals in the Environment and with the European One Health Action Plan against Antimicrobial Resistance (AMR), also set the inclusion of the sulfonamide antibiotic sulfamethoxazole, the diaminopyrimidine antibiotic trimethoprim, the antidepressant venlafaxine together with its metabolite $\mathrm{O}$-desmethylvenlafaxine, and a group of ten azole pharmaceuticals.

The abovementioned initiatives point to the importance of research on suitable approaches to reduce the entrance of pharmaceuticals into the environment. In general, upstream (before release) and downstream (after release) strategies may be adopted for pollution control, with the first being preferred and more effective. However, in the case of medicines, although some improvements may be made before release, namely concerning manufacture, distribution, prescription, consumption or management, and albeit education campaigns are very important [5], restrictions cannot be applied in the same way as for other pollutants since pharmaceuticals are essential to satisfy the population's health care needs. Not to mention that owing to the global population growth and aging, their consumption has an increasing trend $[3,8]$. Therefore, apart from the upstream strategies, feasible approaches are necessary for the efficient removal of pharmaceuticals from water, which constitutes an actual and great challenge for researchers and engineers working on wastewater treatment.

In the described context, this Special Issue (SI) aimed to provide a platform for scientists to bring forth abatement strategies and treatments, either conventional or alternative, for the removal of pharmaceuticals from water and to discuss treatments' efficiency and the fate of this sort of pollutants.

\section{Overview of the Special Issue}

Seven high-quality works were published within the SI on "Removal of Pharmaceuticals from Water: Conventional and Alternative Treatments", which consisted of two review papers $[9,10]$ and five research manuscripts covering a wide range of topics related to pharmaceuticals' pollution, fate, abatement strategies, removal treatments, and/or efficiency assessment [11-15].

The two review articles in the collection dealt with two different types of treatment applied for the removal of pharmaceuticals in general [9], or antibiotics in particular [10]. Silva et al. [9] made a wide review of the literature about the use of biological matrices, namely algae and fungi, with a special focus on bioremediation and biosorption. The authors highlighted the advantages of these treatments, such as the low capital investment and the simple and relatively cheap operation. The use of fungus and microalgae for pharmaceuticals' bioremediation, specifically named mycoremediation and phycoremediation, was thoroughly reviewed, covering aspects such as treatment systems, removal mechanisms, factors influencing degradation capability, and future challenges. As for biosorption, advantages, such as avoiding nutrient supply and the generation of transformation products, were pointed out. Fungus and algal cells for the biosorption of pharmaceuticals, treatment systems, removal mechanisms, influencing factors, and biosorption potential were reviewed. Final remarks pointed out that most of published literature deals with laboratory-scale works and synthetic aqueous media so real applications need to be studied; research into the mechanisms and the dependence on physicochemical and biological factors is still necessary; and, finally, genetic engineering should be considered to select the most efficient strains or to modify fungi and algae to be more efficient [9]. For their part, Cuerda-Correa et al. [10] provided a comprehensive review on advanced oxidation 
processes (AOP) applied for the removal of antibiotics, which were selected as targets due to their recalcitrant properties and actual concern about antimicrobial resistance. AOP were presented as new, sustainable, and clean water purification technologies with large versatility and a broad spectrum of applicability. Catalytic and non-catalytic processes are included within AOP, which stand on the high oxidizing capacity of the hydroxyl radical, differing in how this radical is generated. In this sense, published studies on photolysis, ozone $\left(\mathrm{O}_{3}\right)$ based, hydrogen peroxide $\left(\mathrm{H}_{2} \mathrm{O}_{2}\right)$ based, heterogeneous photocatalysis, sonochemical, and electrooxidative AOP were reviewed. For each group, different treatments for antibiotics' removal were presented, with the corresponding mechanisms stated, their efficiencies reported, and specific remarks on their performance discussed. As the previous review [9], this also indicated that most published literature was on bench- or pilot-scale studies, with the implementation of AOP at full-scale, still being quite limited [10]. The main goal regarding AOP is to lower overall cost per unit mass of pollutant that is removed, for which achievement, Cuerda-Correa et al. [10] presented three main challenges, namely avoiding unnecessary expenses, reducing energy consumption, and minimizing resulting wastes, and gave suggestions to achieve them.

Among the research articles included in the SI, two of them [11,12] were related to the fate of pharmaceuticals under conventional WWTP. Al-Qaim et al. [11] analyzed nine pharmaceuticals in Malaysian surface water, sewage treatment plant (STP) influent, STP effluent, and hospital effluent. For this purpose, a single solid-phase extraction followed by an accurate and selective liquid chromatography-time of flight/mass spectrometry (LC-ToF/MS) method was developed. The studied pharmaceuticals were atenolol and metoprolol ( $\beta$-blockers), acetaminophen (analgesic), caffeine and theophylline (stimulants), sulfamethoxazole (antibiotic), prednisolone (steroidal anti-inflammatory), ketoprofen (nonsteroidal anti-inflammatory), and glibenclamide (antidiabetic), which were shown to have different doses and consumption patterns. Quantification limits of the developed methodology in STP influent, STP effluent, surface water, and drinking water samples respectively averaged $29,16,7$, and $2 \mathrm{ng} \mathrm{L}^{-1}$. The most frequently detected pharmaceuticals were nonprescription, namely acetaminophen $(75 \%)$, theophylline $(100 \%)$, and caffeine $(83.3 \%)$, in which respective mean concentrations were 74,38 , and $540 \mathrm{ng} \mathrm{L}^{-1}$. In addition, atenolol, metoprolol, acetaminophen, caffeine, theophylline, and sulfamethoxazole were detected in surface water, STP influent, and STP effluent, with lower mean concentrations in STP effluents than in STP influents, indicating that they were partly removed in the oxidation ditch of the STP. Regarding hospital effluents, pharmaceuticals' mean concentrations were all higher than in STP effluents, which authors related to the relatively low removal efficiency of the rotating biological contractor in the hospital WWTP. Al-Qaim et al. [11] highlighted that the highest determined concentrations were those of caffeine and acetaminophen (8700 and $4919 \mathrm{ng} \mathrm{L}^{-1}$, respectively) in STP influent, which was linked to their high consumption patterns. As for Hofman-Caris et al. [12], they provided an extensive case study on the origin, fate, and control of pharmaceuticals in the river Meuse (The Netherlands), its tributaries, and a drinking water treatment plant (DWTP) downstream. In this work, and for the very first time, after determining the concentration of pharmaceuticals and metabolites in the tributaries, their apportionments to the DWTP intake were estimated and then verified. This relevant and integrative study comprised four steps: (i) compilation of pharmaceuticals and metabolites concentration in effluents from several WWTP; (ii) assessment of loads in the river Meuse and tributaries, with apportionment of WWTP contributions to the DWTP intake; (iii) evaluation of abatement options, including drinking and wastewater treatments; and (iv) presentation of short and long term solutions. Large divergences were found between different WWTP regarding pharmaceuticals' concentrations, with some of them being extremely difficult to remove (for example, diatrizoic acid, metoprolol, or diclofenac). WWTP were proved to contribute to pharmaceuticals loads in the river Meuse significantly. Contributions of the Meuse and tributaries to the concentration of pharmaceuticals and metabolites in the intake of the DWTP were estimated, evidencing that the river Meuse had the largest input. Authors proposed abatement options at WWTP 
along the tributaries and in the DWTP, indicating their effectiveness, costs, advantages, and disadvantages. Adding refinement treatments able to remove pharmaceuticals at every WWTP in the catchment was highlighted as the best option, also granting good chemical and ecological status in the river and making additional treatments in the DWTP dispensable. In this sense, incorporating an $\mathrm{AOP}$, namely $\mathrm{UV} / \mathrm{H}_{2} \mathrm{O}_{2}$, after removing organic matter by ion exchange was presented as an efficient alternative at a fair spending (increasing costs by about $0.23 € \mathrm{~m}^{-3}$ of treated water).

The other three research articles of the SI [13-15] are experimental works on alternative treatments for the removal of pharmaceuticals and with a special focus on sustainability. Coimbra et al. [13] studied the biosorption of diclofenac, a nonsteroidal anti-inflammatory drug included in the first watch list (Decision 2015/495/EU), onto residual microalgae biomass of two different genera, viz. Synechocystis sp. and Scenedesmus sp. As highlighted by the authors, the implementation of microalgae systems for $\mathrm{CO}_{2}$ fixation is limited by high costs, which may be reduced using wastewater as culture media, namely, as a source of water and nutrients. To further increase these systems' sustainability and in line with the circular economy paradigm, the residual (dead) microalgae biomass must be given a use. Its utilization as a pharmaceuticals' biosorbent was proposed, and both kinetic and equilibrium experiments were carried out under batch operation. Obtained results respectively fitted the pseudo-second kinetic order and the Langmuir isotherm. Synechocystis sp. and Scenedesmus sp. biomasses showed similar kinetic performance, with Scenedesmus sp. biomass attaining higher diclofenac sorption capacity at equilibrium $\left(28 \mathrm{mg} \mathrm{g}^{-1}\right)$ than Synechocystis sp. biomass $\left(20 \mathrm{mg} \mathrm{g}^{-1}\right)$. These values were shown to be lower than by commercial activated carbon but comparable to published results for waste-based activated carbons even when microalgae biomass was not chemically nor thermally modified or treated before use [13]. Thus, microalgae biomass application as a biosorbent was highlighted as a sustainable alternative, also favoring the zero-waste cultivation of microalgae. Kebede et al. [14] carried out a novel study on the biosorption of antibiotics, viz. sulfanilamide, marbofloxacin, ciprofloxacin, danofloxacin, oxytetracycline, sulfadimethoxine, sulphacetamide, sulfamonomethoxine, sulfamethoxazole, tylosin, and sulfamerazine, using water-soluble proteins from the seeds of Moringa stenopetala. Moreover, the surface functional groups of water-soluble protein powder before and after adsorptive use were determined by Fourier transform infrared (FTIR). Under optimized conditions, the simultaneous removal of selected antibiotics from synthetic and real wastewater was investigated. Maximum removals in the range of $85 \%-96 \%$ were determined, which decreased to $70 \%-82 \%$ in real wastewater samples. The authors pointed out that the proposed treatment was simple, cost-effective, environmentally friendly, and easily applicable, with Moringa stenopetala cultivation contributing towards deforestation reduction. Finally, Escapa et al. [15] assessed the efficiency of different microalgae strains, namely Chlorella sorokiniana (CS), Chlorella vulgaris (CV), and Scenedesmus obliquus (SO), in the treatment of water contaminated with acetaminophen, which is a widely used nonprescription analgesic and antipyretic. As remarked by authors, microalgae may be used for green eco-friendly water treatment, with assets such as photoautotrophic growth, few operational requirements, $\mathrm{CO}_{2}$ fixation, and generation of both high-value sub-products and profitable biomass. In this work, water was treated under batch conditions in bubbling column photobioreactors run at a semi-pilot scale. Accounting for the possible generation of transformation products from acetaminophen biodegradation, the treatment efficiency was not only determined in terms of removal but also toxic effects on zebrafish (Danio rerio) embryo, namely at the gastrula, pharyngula, larval and juvenile stages. At the end of the batch, acetaminophen concentration decreased by an average of $67 \%, 39 \%$, and $17 \%$ under the cultivation of $\mathrm{CS}, \mathrm{SO}$, and $\mathrm{CV}$, respectively. In the same way, the incidence of toxic effects on zebrafish embryos was $\mathrm{CS}<\mathrm{SO}<\mathrm{CV}$, which confirmed $\mathrm{CS}$ as the most efficient. Moreover, toxic effects determined for microalgae treated effluents were equal to those of synthetic solutions with equivalent acetaminophen concentrations, which allowed the 
conclusion that acetaminophen biodegradation by $\mathrm{CS}, \mathrm{SO}$ and $\mathrm{CV}$ did not result in toxic transformation products for zebrafish embryo.

Globally, this SI on "Removal of Pharmaceuticals from Water: Conventional and Alternative Treatments" pointed out the interest of the scientific community about finding efficient treatments and strategies for the removal of pharmaceuticals from water. Apart from such a challenge, this SI has also reflected researchers' concern about the treatments' sustainability from both the environmental and economic points of view and the importance of implementing integrated approaches. Furthermore, it is underlined that AOP and bioremediation received special attention in this SI, having been featured as promissory treatments in the articles here gathered.

Author Contributions: M.O., C.E. and R.N.C., as Guest Editors of the Special Issue entitled "Removal of Pharmaceuticals from Water: Conventional and Alternative Treatments", contributed to the preparation of this Editorial. Conceptualization, M.O., C.E. and R.N.C.; writing-original draft preparation, R.N.C., C.E. and M.O.; writing-review and editing, M.O.; Supervision, M.O. All authors have read and agreed to the published version of the manuscript.

Funding: Thanks are due to the Portuguese Fundação para a Ciência e a Tecnologia/Ministério da Ciência, Tecnologia e Ensino Superior (FCT/MCTES) for the financial support to the Associated Laboratory CESAM (UIDP/50017/2020+UIDB/50017/2020) through national funds. Funding through the FCT Investigator Program (IF/00314/2015) is also acknowledged.

Institutional Review Board Statement: Not applicable.

Informed Consent Statement: Not applicable.

Data Availability Statement: Data sharing is not applicable to this article.

Acknowledgments: The contributions to this Special Issue (SI) are acknowledged with thanks. We would like to express our appreciation to the authors of these contributions for their commitment and superb work. Thanks are also due to the anonymous reviewers who gently revised the submissions to this SI for their time and selfless dedication. Finally, our most sincere gratitude to the editorial managers, who so kindly assisted the assembling of this SI. As guest editors, we are very happy with the final result.

Conflicts of Interest: The authors declare no conflict of interest. 


\section{References}

1. Rodell, M.; Famiglietti, J.S.; Wiese, D.N.; Reager, J.T.; Beaudoing, H.K.; Landerer, F.W.; Lo, M.H. Emerging trends in global freshwater availability. Nature 2018, 557, 651-659. [CrossRef] [PubMed]

2. Warner, W.; Licha, T.; Nödler, K. Qualitative and quantitative use of micropollutants as source and process indicators. A review. Sci. Total Environ. 2019, 686, 75-89. [CrossRef] [PubMed]

3. Pereira, A.; Silva, L.; Laranjeiro, C.; Lino, C.; Pena, A. Selected pharmaceuticals in different aquatic compartments: Part I-Source, fate and occurrence. Molecules 2020, 25, 1026. [CrossRef] [PubMed]

4. Santos, L.H.M.L.M.; Araújo, A.N.; Fachini, A.; Pena, A.; Delerue-Matos, C.; Montenegro, M.C.B.S.M. Ecotoxicological aspects related to the presence of pharmaceuticals in the aquatic environment. J. Hazard. Mater. 2010, 175, 45-95. [CrossRef] [PubMed]

5. Courtier, A.; Cadiere, A.; Roig, B. Human pharmaceuticals: Why and how to reduce their presence in the environment. Curr. Opin. Green Sustain. Chem. 2019, 15, 77-82. [CrossRef]

6. Yang, Y.; Ok, Y.S.; Kim, K.H.; Kwon, E.E.; Tsang, Y.F. Occurrences and removal of pharmaceuticals and personal care products (PPCPs) in drinking water and water/sewage treatment plants: A review. Sci. Total Environ. 2017, 596-597, 303-320. [CrossRef] [PubMed]

7. Luo, Y.; Guo, W.; Ngo, H.H.; Nghiem, L.D.; Hai, F.I.; Zhang, J.; Liang, S.; Wang, X.C. A review on the occurrence of micropollutants in the aquatic environment and their fate and removal during wastewater treatment. Sci. Total Environ. 2014, 473-474, 619-641. [CrossRef] [PubMed]

8. Quesada, H.B.; Baptista, A.T.A.; Cusioli, L.F.; Seibert, D.; de Oliveira Bezerra, C.; Bergamasco, R. Surface water pollution by pharmaceuticals and an alternative of removal by low-cost adsorbents: A review. Chemosphere 2019, 222, 766-780. [CrossRef] [PubMed]

9. Silva, A.; Delerue-Matos, C.; Figueiredo, S.A.; Freitas, O.M. The use of algae and fungi for removal of pharmaceuticals by bioremediation and biosorption processes: A review. Water 2019, 11, 1555. [CrossRef]

10. Cuerda-correa, E.M.; Alexandre-franco, M.F.; Fern, C. Antibiotics from Water. An Overview. Water 2020, 12, 1-50.

11. Al-Qaim, F.F.; Mussa, Z.H.; Yuzir, A.; Abu Tahrim, N.; Hashim, N.; Azman, S. Transportation of different therapeutic classes of pharmaceuticals to the surface water, sewage treatment plant, and hospital samples, Malaysia. Water 2018, 10, 916. [CrossRef]

12. Hofman-Caris, R.; ter Laak, T.; Huiting, H.; Tolkamp, H.; de Man, A.; van Diepenbeek, P.; Hofman, J. Origin, fate and control of pharmaceuticals in the urban water cycle: A case study. Water 2019, 11, 1034. [CrossRef]

13. Coimbra, R.N.; Escapa, C.; Vázquez, N.C.; Noriega-Hevia, G.; Otero, M. Utilization of non-living microalgae biomass from two different strains for the adsorptive removal of diclofenac from water. Water 2018, 10, 1401. [CrossRef]

14. Kebede, T.G.; Dube, S.; Nindi, M.M. Removal of multi-class antibiotic drugs from wastewater using water-soluble protein of moringa stenopetala seeds. Water 2019, 11, 595. [CrossRef]

15. Escapa, C.; Coimbra, R.N.; Neuparth, T.; Torres, T.; Santos, M.M.; Otero, M. Acetaminophen removal from water by microalgae and effluent toxicity assessment by the zebrafish embryo bioassay. Water 2019, 11, 1929. [CrossRef] 